\title{
MUHAMMADIYAH DAN ADAT TANAH ULAYAT MINANGKABAU
}

\author{
Oleh: Iza Hanifuddin* \\ Jurusan Syariah STAIN Ponorogo \\ J1. Pramuka No. 156 Kecamatan Ponorogo, Kabupaten Ponorogo, Jawa Timur 63471 \\ e-mail: izahanifuddin@yahoo.com
}

\begin{abstract}
Minangkaubaunese has believed the importance of land for centuries. Rules concerning with land within the life of Minangkabaunese traditionally can be said to be genuine community. Lands, as they believe, is basically a symbol of their own identity which is called ulayat. Furthermore, land is one of the institutional elements of matrilineal system which determines individual and communal integrity, and original and migrant residents to base any decision dealing with succeeding the right of particular region. According to rules, land are not to be sold or used for as a warranty the purpose of making loans. The influence of Muhammdiyah toward Minangkabau has colored the pattern and offered new model of the management of ulayat from succeeding communal to organizational communal by keeping the tradition concerning with the status of waqf and probibition to be sold and diminished. All land assets, therefore, are in the control of business division of Mubammadiyah.
\end{abstract}

Kata kunci: kaum tua, kongres Minangkabau, Islam abangan, madrasah al-muballigbin, eigendom

\section{PENDAHULUAN}

$\mathscr{P}$ eradaban awal masyarakat asli adalah berburu hewan dan ikan atau mengambil hasil hutan untuk hidup. Tanah bagi mereka tidak terlalu penting kecuali setelah pola hidup mereka sudah berpindah menjadi masyarakat tani. Bagi masyarakat asli yang sudah hidup dengan pola pertanian dan masyarakat adat secara umum, tanah merupakan bahan alam yang amat berharga dalam pengertian-pengertian maknawi berkaitan budi dan kemuliaan hati. Persepsi mereka tentang tanah ini telah membentuk berbagai kebiasaan dan undangundang adat berkaitan tanah yang berfungsi mengatur penggunaan tanah dan sumber alam lainnya agar tidak digunakan sewenang-wenang. Filsafat adat mengajarkan nilai-nilai yang agak universal sifatnya. Hak terhadap tanah mencerminkan tanggung jawab keluarga, kelompok, dan pengelola secara bersama. Tanah mesti dipelihara untuk generasi yang akan datang, tidak boleh dieksploitasikan secara habis-habisan sehingga menyebabkan terputusnya hubungan antara generasi mendatang dengan keturunan nenek moyang. Menurut adat, tanah tidak boleh dijualbeli atau dimiliki secara pribadi, di mana tanah merupakan milik komuniti yang digunakan

* Penulis adalah Dosen pada STAIN Ponorogo 
secara bersama oleh komuniti. Inilah sebagian dari nilai-nilai filsafat adat yang mereka pegangi yang di mana pada hari ini sudah mulai terkikis akibat pembangunan dan maraknya pemilikan tanah secara pribadi (Hasan Mat Nor, 1996: 54).

Masyarakat Minangkabau telah melihat pentingnya tanah sejak zaman dahulu. Konsep peraturan adat berkaitan harta dan tanah yang ada dalam kehidupan masyarakat Minangkabau secara tradisional dapat dikatakan masih dalam taraf masyarakat asli. Tanah bagi mereka merupakan simbol adat itu sendiri.

Dalam penjelasan konsep harta di atas dapat diperoleh gambaran bahwa harta pusaka ada dua, yaitu tanah dan bukan tanah. Kategori tanah termasuk apa yang tumbuh di atasnya, apa yang ada di dalamnya, dan apa yang ada di atasnya. Kategori bukan tanah, yaitu harta tak bergerak seperti rumah dan harta bergerak seperti keris, pakaian, penghulu, dan yang berkaitan gelar kebesaran. Kendaraan dan ternak termasuk kategori harta bergerak, tetapi tidak ada hubungannya dengan gelar kebesaran. Dengan demikian, tanah menduduki tempat yang penting dalam hal harta pusaka. Bagi masyarakat adat Minangkabau, tanah adalah salah satu simbol dan unsur institusi adat matrilineal, penentu martabat seseorang dan suku, penentu status penduduk asli dan tidak asli yang berfungsi sebagai dasar penentu pewarisan hak-hak kebesaran negeri (A. M. Datuk Maruhum Batuah \& D. H. Bagindo Tanameh, 1954: 41).
Sebagai organisasi yang lahir di Jawa, Muhammadiyah yang sering diidentikkan sebagai gerakan Islam modernis dianggap tepat berada di Minangkabau yang merupakan pusat lahirnya gerakan Islam modern di Nusantara. Sering didengar bahwa kultur keislaman masyarakat Minangkabau ialah Muhammadiyah. Oleh karena itu, melihat hadirnya Muhammadiyah di Minangkabau ini yang sudah cukup lama, akan coba dilihat bagaimana sejarah Muhammadiyah menjelaskan pemikiran dan menunjukkan praktek-prakteknya berkaitan adat tanah ulayat yang sudah menjadi sistem yang lebih lama lagi membumi di Minang Kabau.

\section{SEKILAS SEJARAH KEDATANG- AN MUHAMMADIYAH DI MINANGKABAU}

Muhammadiyah hadir di Minangkabau pada tahun 1925 sepulang kunjungan Haji Abdul Karim Amrullah ke Yogyakarta untuk menjumpai KH. Ahmad Dahlan sebagai seorang sahabat yang sama-sama pernah belajar kepada Shaykh Ahmad Khatib alMinangkabawi. Muhammadiyah sendiri didirikan pada tahun 1912 di Yogyakarta. Hubungan rapat ini kerana kedua-dua beliau mempunyai tujuan dan perjuangan yang sama. Bahkan, KH. Ahmad Dahlan berlangganan Majalah Al-Munir yang beliau kelola bersama Haji Abdullah Ahmad. Sejarah pertemuan ini bermula ketika menantu beliau, yaitu Ahmad Rasyid Sutan 
Mansur (A.R. Sutan Mansur) telah mengenal dan menjadi anggota Muhammadiyah langsung dari pendirinya, yaitu KH. Ahmad Dahlan sejak 1921 sehingga akhirnya menjadi pengurus organisasi ini di Pekalongan (Hamka, 2006: 231).

Muhammadiyah di Sumatera Barat pertama kali berdiri di Sungai Batang Maninjau, kampung Haji Abdul Karim Amrullah dan menyebar ke perkampungan sekitar danau Maninjau, seperti Matur, Palembayan, Lawang, Sungai Landir, sehingga akhirnya ke Agam. Sekalipun tidak menjadi anggota Muhammadiyah, beliau diakui sebagai pembawa Muhammadiyah ke Sumatera Barat dan pelindung organisasi ini bersama Shaykh Jamil Jambek. Oleh karena itu, saran dan nasehat beliau sering dijadikan pertimbangan oleh pengurus Muhammadiyah.

Di antara tokoh Muhammadiyah yang lahir di daerah ini, yaitu Hamka, anak Haji Abdul Karim Amrullah, AR. Sutan Mansur, menantu beliau yang menjadi pengurus besar Muhammadiyah Pusat, Yusuf Amrullah, sang adik yang menjadi ketua Muhammadiyah di Maninjau, Zain Jambek, pemimpin utama Muhammadiyah, Jamilah Jambek, pengurus besar bahagian Aisyiah Muhammadiyah, Zainal Abidin Jambek, konsul Muhammadiyah di Palembang, Saaduddin Jambek, pengurus Muhammadiyah bagian pengajaran. Bahkan, orang-orang terkenal di Muhammadiyah pusat juga banyak yang berasal dari Sumatera Barat (Hamka, 1967: 163-164).

Kedudukan Haji Abdul Karim Amrullah yang seperti sudah dijelaskan membuat beliau sangat leluasa memberikan kritikannya kepada pengurus Muhammadiyah yang dikatakannya tersangat taklid kepada setiap keputusan Muhammadiyah pusat yang ada di Yogyakarta. Salah satu amalan yang dianggap taklid ialah pengumpulan zakat secara terancang. Menurut beliau, zakat tidak boleh dikumpulkan seperti demikian, semua terserah kepada pemberi zakat, hendak ke mana dan kepada siapa zakat tersebut diberikan. Kritikan lainnya ialah perempuan Aisyah suka pergi ke mana-mana dalam organisasi tanpa ditemani oleh mahram-nya, perempuan menyampaikan ucapan di hadapan kaum lelaki, perempuan turut salat Idul Fitri di lapangan, dan sebagainya sehingga beliau mesti menuliskan kritikannya ini dalam karya tulis bertajuk: Cermin Terus, Berguna untuk Pengurus, Pencari Jalan yang Lurus. Buku ini telah mendatangkan protes dari kaum perempuan kerana buku tersebut dianggap telah melecehkan mereka dan model pakaian mereka. Buku ini juga dianggap sebagai buku cabul yang disejajarkan dengan buku Sumandari-Suroto yang terbit pada masa itu dan diprotes oleh masyarakat kerana melecehkan Nabi Muhammad saw. Para perempuan ini memprotes dan bergabung dalam SKIS (Serikat Kaum Ibu Sumatera) bersama MTKAAM (Majelis Tinggi Kerapatan Adat Alam Minangkabau) yang diketuai oleh seorang tokoh adat, Datuk Simarajo. Bahkan, H. Mahmud Yunus juga sempat membahas buku tersebut dalam forum diskusi di surau Shaykh Jamil Jambek Bukittinggi (Hamka, 1967: 164-175). 
Ketika Muhammadiyah mulai berkembang luas di Sumatera Barat, Shaykh Muhammad Zain, salah seorang Kaum Tua juga turut serta menjadi anggota dan membawa Muhammadiyah tersebut ke Simabur. Banyak penghulu yang ikut dalam persyarikatan ini, antara lain Datuk Majo Indo (Kepala Nagari Simabur), Datuk Mangkuto Majolelo, dan Datuk Bungsu. Bahkan, di Simabur ini mereka berjaya mendirikan HIS (Sekolah Rakyat) Muhammadiyah. Melalui propaganda SJ. Sutan Mangkuto, Shaykh Muhammad Jamil Jaho akhirnya juga bergabung sebagai anggota Muhammadiyah. Ketika kemudian diketahui bahwa Kaum Muda telah menjadikan Muhammadiyah sebagai alat untuk menyebarkan faham pembaharuannya (Ken Young, 1994: 106). Kaum Tua akhirnya banyak yang keluar dari Muhammadiyah dan mendirikan organisasi lain, yaitu Perti (Persatuan Tarbiyah Islamiyah).

Muhammadiyah mulai memastikan keberadaannya di Minangkabau ketika sukses mengadakan Kongres Muhammadiyah ke-19 di Bukittinggi pada 14-21 Maret 1930 dengan ketua kongres, Muhammad Zain Jambek. Kongres dihadiri oleh pengurus Muhammadiyah seluruh Nusantara di mana secara umum berasal dari perantau Minang. Oleh karena itu, Hamka mengistilahkan kongres ini sebagai "Kongres Minangkabau" (Hamka, 2006: 268, 281, dan 286). Delapan tahun setelah Muhammadiyah berdiri di Sumatera Barat dilaporkan bahwa Muhammadiyah diakui sebagai persyarikatan yang paling banyak memiliki sekolah, yaitu 122 sekolah. Bandingkan dengan Persatuan Muslimin Indonesia yang hanya memiliki 4 sekolah, Diniyyah 120 sekolah, Thawalib 44 sekolah, dan institusi pendidikan yang diasaskan oleh Kaum Tua 45 sekolah (Azyumardi Azra, 2003: 22).

\section{MUHAMMADIYAH DAN ADAT ULAYAT}

Berkaitan amalan adat, kaum modern Muhammadiyah sebagaimana dilaporkan oleh Peacock telah memandang bahwa adat matrilineal Minangkabau sama dengan Islam Abangan di Yogyakarta (Ken Young, 1994: 95). Selain ini, pikiran-pikiran Muhammadiyah lebih banyak disampaikan oleh tokoh sentralnya, yaitu Hamka. Pada masa ini, ungkapan bahwa adat lama tak lekang oleh panas, tak lapuk oleh hujan telah dijadikan sebagai perkataan hiasan oleh para pecinta adat dan bahan cemoohan oleh para pembenci adat. Hamka pernah menyindir bahwa yang tidak lekang oleh panas dan tidak lapuk oleh hujan hanyalah batu. Batu juga akan berubah jika terus menerus dititis oleh air hujan dan panas (Hamka, 1963: 62). Sekalipun terdapat pihak yang mencintai dan membenci adat, adat Minangkabau tetap berdiri dengan gagah sehingga hari ini. Kemegahan adat mesti ditentukan oleh masyarakat adatnya sendiri. Ungkapan adat mengajarkan agar adat dipelihara dan dipertahankan, usang diperbaharu, lapuk dikajangi (A. M. 
Datuk Maruhum Batuah \& D. H. Bagindo Tanameh, t.th.: h. cover).

Dalam tulisannya tentang adat Minangkabau menghadapi revolusi, Hamka pernah menyampaikan kekesalan dan penilaian negatifnya terhadap sistem pemilikan tanah adat di Minangkabau. Namun, secara cepat beliau segera membetulkan kekesalan ini melalui tulisan lain dengan mengatakan bahwa hukum adat Minangkabu itu indah (Hermayulis, Kertas Kerja Seminar, 2000: 2). Saya memuji adat, saya mencintai sistem harta pusaka, tetapi anak Minang sendiri sudah tidak dapat lagi menumpangi bahtera itu, katanya (Hamka, 2006: 141). Di tempat lain, lebih tegas Hamka mengatakan bahwa semua persoalan di Minangkabau disebabkan oleh sistem harta pusaka yang dimiliki oleh suku dan sistem adat matrilineal. Semua keadaan mesti berubah termasuk adat juga harus berubah (Hamka, 2006: 145).

Pada sudut lain Hamka juga pernah menyatakan bahwa para tokoh Paderi yang berperang atas nama Islam tidak pernah mempersoalkan kewujudan tanah ulayat. Nampaknya, Hamka setuju dengan cara-cara para tokoh Paderi ini. Tapi, beliau masih juga mengatakan bahwa adat lama berkaitan pusaka kepada kemenakan tidak dapat dipertahankan lagi kerena pandangan hidup telah berubah, yaitu lebih dekat kepada pewarisan Islam. Selain itu, kuasa ninik mamak hari ini tidaklah sebagaimana dahulu lagi. Pihak penguasa juga telah membuatkan peraturan tentang tanah, yaitu landreform (Hamka, 2006: 91). Adat matriarchaat akan hilang dan berakhir (Hamka, 2006:
95). Sekalipun Hamka memuji bahwa kekuatan Minangkabau terletak pada adat dan agamanya. Tetapi beliau menjelaskan sebaliknya di mana yang dimaksud sebagai adat ialah pusaka lama yang tidak dapat dipertahankan lagi itu. Minangkabau pasti berubah. Adat pusaka kepada kemenakan tidak dapat dipertahankan lagi kerana mamak tidak mempunyai kekuasaan lagi dan anak yang lahir pasca revolusi tidak mengenali adatnya lagi. Minangkabau moden akan berdiri di atas Minangkabau lama (Hamka, 1985: 76-77). Suatu ungkapan pasrah dengan kondisi yang dikesan tidak memiliki rasa kepedulian untuk memperbaikinya.

Hamka menekankan bahwa orang Minangkabau telah merasakan pengalaman pahit di kampung sendiri kerana pelayanan adat yang tidak mengena di hati sehingga mereka lebih memilih merantau. Di rantau, mereka mendapat pengalaman baru karena dapat membina keluarga inti dengan prinsip patrilineal di mana ayah adalah kepala rumah tangga yang memiliki tanah tanpa pengaruh mamak dan kemenakan. Ketika seperti ini, hubungan mereka dengan adat menjadi renggang dan melihat adat tidak sesuai lagi dengan perubahan yang ada pada masa kini (Hamka, 2006: 37).

Pandangan beliau ini mengisyaratkan kebimbangan antara benci dengan rindu kepada adat. Hamka tidak mengecam adat, tetapi telah meratapi adat yang sudah tua dan waktunya masuk kubur. Dunia sudah berubah, adat juga akan berubah. Akhirnya, Hamka menegaskan bahwa semua persoalan di Minangkabau bermula daripada 
harta pusaka dan matriarchaat. Jangan mendustai diri, katanya (Hamka, 1985: 118). Padahal menurut adat, sistem matriarchaat tidak dapat dipisahkan dengan sistem pusaka tinggi. Selama harta pusaka tinggi dan penguasaannya masih kukuh, selama itu pula adat yang tak lapuk dek hujan dan tak lekang dek panas akan dapat dipertahankan (Hamka, 1985: 59).

Sebagaimana Shaykh Ahmad Khatib al-Minangkabawi, Shaykh Thahir Jalaluddin, Haji Abdul Karim Amrullah, Hamka muda masih menunjukkan pendirian anti adat sehingga sering mendapat tentangan daripada kaum adat. Hamka pernah menulis buku Adat Minangkabau Menghadapi Revolusi untuk mengkritik sistem adat (Hamka, 1963: 62). Ketika masa tua, ternyata Hamka masih dapat menangis jika menyanyikan lagu bakaba dan masih mau diangkat menjadi seorang penghulu dengan gelaran Datuk Indomo. Sebelum Hamka, juga terdapat tokoh lain yang lebih suka mengkritik adat, baik secara halus maupun kasar, bahkan radikal. Mereka itu ialah Shaykh Ahmad Khatib al-Minangkabawi, Shaykh Djalaluddin, dan Haji Abdul Karim Amrullah, ayah Hamka. Digambarkan bahwa sebagian mereka masih mencintai dan merindukan kampung halamannya, tetapi tidak mau pulang untuk selamanya. Taufik Abdullah menggambarkan hubungan perantau ini dan negeri asalnya sebagai hubungan "cinta" dan "benci" yang sangat aneh (A. A. Navis, 1986: xx). Gaya hubungan "cinta dan benci" adat ini juga terjadi pada pribadi Sutan Syahrir yang lebih suka disebut sebagai orang Banda Naire daripada sebagai orang Minangkabau dan H. Agus Salim yang tidak mau menginjakkan kakinya di Minangkabau sampai mati. (Herwandi \& Zaiyardam Zubir, 2006: 101). Sekalipun ramai tokoh anti adat yang mempersoalkan kedudukan lelaki dalam rumah tangga Minangkabau dan harta pusaka dengan sistem matrilineal-nya dan menganggapnya sebagai adat jahiliyyah menurut syarak, tetapi mereka masih suka menyebutnyebut ungkapan adat, yaitu adat basandi syarak, syarak basandi kitabullah dan tanah pusaka dibahagi secara adat, tanah sepencarian dibahagi secara syarak dalam pelbagai kesempatan dan seminar (Muchtar Naim, Kertas kerja Seminar, 2000: 9).

Berkaitan sejarah Muhammadiyah, Hamka pernah mengkritik tulisan MD. Mansur bertajuk Sejarah Minangkabau yang dianggap sebagai tulisan sejarah yang kacau karena banyak kesalahan, khususnya tentang Muhammadiyah di Minangkabau. Menurut MD. Mansur, Muhammadiyah di Minangkabau tidak mempunyai pendirian tegas terhadap Belanda sebagaimana Persatuan Tarbiyah Islamiyyah (Perti), Persatuan Muslimin Indonesia (Permi), dan Komunis. Disebutkan bahwa Muhammadiyah itu tidak gentle dan berpendirian mendua. Oleh karena itu, Muhammadiyah mengalami kemunduran pada tahun 1927 dan tahun-tahun setelahnya. Menurut Hamka bahwa justru Muhammadiyah 
ketika itu sedang mengalami kemajuan karena pada tahun 1930 dapat melaksanakan Kongres Muhammadiyah ke-19 di Bukittinggi dan pada masa itu orang mula menyebut istilah "Muhammadiyah di Nagarikan, Nagari di Muhammadiyahkan" (Hamka, 2006: 301-305).

Muhammadiyah membina sekolah pertama kali di Muara Pauh Bandar Air Sungai Ligin Maninjau pada tahun 1926 dengan nama Madrasah al-Muballighin, yaitu di atas tanah Suku Caniago. Cara yang ditempuh oleh Muhammadiyah adalah dengan meminta fatwa kepada ulama dan kato penyalasai kepada penghulu mengikuti ungkapan adat kato penghulu kato manyalasai, kato ulama kato hakikat. Dengan cara ini, Muhammadiyah telah mengisi adat dan menuang lembaga, yaitu membayar uang adat sebesar 700 gulden. Amalan ini diistilahkan oleh Hamka sebagai amalan ibahah. Sejak itu, cara yang sama telah digunakan oleh Muhammadiyah untuk mengembangkan dan membina sekolahsekolah Muhammadiyah di Minang Kabau. Bertemulah konsep adat sepanjang jalan yang diperkuat oleh dalil adat, yaitu balai nan saruang, masjid nan sabuah dengan sekolah nan salokal. (Hamka, 2006: 316-318). Muhammadiyah tidak mendirikan masjid sendiri sebagaimana gerakan Kaum Tua-Kaum Muda. Menurut adat, masjid dimiliki oleh nagari, sementara itu nagari sendiri dikuasai oleh Kaum Adat dan Kaum Tua. Dengan demikan, tidak ada peluang bagi Kaum Muda untuk memanfaatkan dan menggunakan masjid nagari. Akhirnya, pembinaan masjid baru oleh Kaum Muda tidak dapat dihindarkan. Terjadilah pembangun- an masjid berdasarkan hak milik masing-masing kelompok tersebut (B. J. O. Schrieke, 1973: 27 dan 75). Masjid nagari digunakan oleh Muhammadiyah karena kebanyakan pengurus Muhammadiyah adalah para penghulu nagari. Pembuatan masjid Muhammadiyah berlangsung pada tahun-tahun terakhir ini ketika sudah tidak seimbang lagi antara jumlah masjid dengan jumlah penduduk.

Di sebagian tempat, Muhammadiyah berdiri secara tidak lancar. Halangan daripada kaum adat sering dijumpai karena mereka takut kepada Belanda jika tidak mematuhi perintah untuk mengontrol gerakan Muhammadiyah sebagaimana juga dilakukan kepada Permi (Persatuan Muslimin Indonesia) dan PSII (Partai Syarikat Islam Indonesia) di mana ia sudah dilarang untuk melakukan musyawarah sejak tahun 1934. Berbagai kasus penghalangan juga terjadi. Di Malalo Palembayan, Nukman Kari Marajo, seorang anggota Muhammadiyah sempat dipukuli oleh masyarakat, di Selaras Air, Sumanik sekolah Muhammadiyah-nya dipaku warga, tidak boleh dibuka, di Air Mati Pasar Solok, warga Muhammadiyah dilarang mendirikan salat Jumat sekalipun di tanahnya sendiri yang berstatus hak milik eigendom (hak milik yang berasal daripada tanah milik Belanda), dan hal serupa berlaku juga di Batu Hampar Kampung Tengah. Semua kasus ini merupakan halangan daripada kaum adat. (Hamka, 2006: 325-333)

Halangan kaum adat bukan hanya berlaku di Minangkabau, tapi juga di Sulawesi. Halangan terbesar di Minangkabau, yaitu di daerah 
Bandar Sepuluh di mana Muhammadiyah enyah dari daerah tersebut dan para pengurusnya diusir dari kampung halamannya, dibuang sepanjang adat oleh Ibrahim Samik, sang pemimpin adat. Di antara mereka ada yang pergi ke Kurinci dan ada yang terpaksa berdiam di Padang. Halangan daripada kaum adat ini juga menjadi bahan pembahasan dalam Kongres Muhammadiyah ke-22 di Semarang yang dalam sarannya disampaikan agar Muhammadiyah berhati-hati menghadapi adat di tempatnya masing-masing. Adat yang baik dipakai dan terus dihidupkan dan adat yang tidak baik dihadapi semampunya. Halangan adat ini mulai mereda setelah penjajah pergi dari bumi Indonesia (Hamka, 2006: 335-336). Kini, tanah-tanah wakaf

\section{DAFTAR KEPUSTAKAAN}

Azra, Azyumardi. 2003. Surau: Pendidikan Islam Tradisional Dalam Transisi dan Modernisasi. Ciputat: PT. Logos Wacana Ilmu.

Batuah, A. M. Datuk Maruhum \& Tanameh, D. H. Bagindo. 1954. Hukum Adat dan Adat Minangkabau. Djakarta: Poesaka Aseli.

Batuah, A. M. Datuk Maruhum \& Tanameh, D. H. Bagindo. t.th. Hukum Adat dan Adat Minangkabau, Luhak Nan Tiga Laras Nan Dua. Jakarta: NV. Poesaka Aseli.

Schrieke, B. J. O.. 1973. Pergolakan Agama Di Sumatra Barat, Sebuah lama Muhammadiyah diketahui bersumber dari tanah eigendom (milik syarikat Belanda) yang dibeli oleh para anggota Muhammadiyah yang kemudian dijadikan wakaf, manakala tanah-tanah Muhammadiyah yang baru berasal daripada wakaf individu dan sebagian berasal dari pembelian yang diwakafkan untuk organisasi Muhammadiyah.

\section{PENUTUP}

Demikian sekilas gambaran tentang sejarah Muhammadiyah di Minangkabau dan kaitannya dengan adat dan tanah ulayatnya. Gambaran sekilas ini untuk kepentingan diskusi awal guna menggali informasi lebih detil selanjutnya.

Sumbangan Bibliografi. Jakarta: Bhratara.

Hamka. 1963. Adat Minangkabau menghadapi revolusi, Firma Teka, Djakarta.

Hamka. 1963. Adat Minangkabau Menghadapi Revolusi. Djakarta: Firma Teka.

Hamka. 1967. Ajahku, Riwayat Hidup Dr. H. Abd. Karim Amrullah dan Perdjuangan Kaum Agama Di Sumatera. Djakarta: Djajamurti.

Hamka. 1974. Muhammadiyah Di Minangkabau. Jakarta: Yayasan Nurul Islam. 
Hamka. 1985. Islam dan Adat Minangkabau. Jakarta: Pustaka Panjimas.

Hamka. 2006. Islam dan Adat Minangkabau. Selangor Darul Ehsan: Pustaka Dini, Sdn. Bhd.

Hermayulis, Tanah ulayat dalam problematik pembangunan: Tanah ulayat sebagai "social asset" dan "capital asset", Kertas kerja Seminar Reaktualisasi Adat Basandi Syarak, Syarak Basandi Kitabullah dalam Pembangunan Sumatera Barat. Hotel Pusako. Bukittinggi, 2223 Januari 2000, hlm. 2.

Herwandi \& Zubir, Zaiyardam. 2006. Menggugat Minangkabau. Padang: Andalas University Press.
Naim, Muchtar, Konflik dan konsensus antara adat dan syarak di Minangkabau, Kertas kerja Seminar Reaktualisasi Adat Basandi Syarak, Syarak Basandi Kitabullah dalam Pembangunan Sumatera Barat. Hotel Pusako. Bukittinggi, 2223 Januari 2000, hlm. 9

Navis, A. A.. 1986. Alam Takambang Jadi Guru, Adat dan Kebudayaan Minangkabau. Jakarta: PT. Pustaka Grafitipers.

Nor, Hasan Mat. 1996. Tanah dan Masyarakat Orang Asli. Selangor. FSSK UKM.

Young, Ken. 1994. Islamic Peasants and State, the 1908 Anti-tax Rebellion In West Sumatra. Connecticut: Yale University Southeast Asia Studies. 